Comment on Prof. Imwinkelried's "Formalism v. Pragmatism in Evidence: Reconsidering the Absolute Ban on the Use of Extrinsic Evidence to Prove Impeaching Untruthful Acts That Have Not Resulted in Conviction": Just What Evidence of Witness Misdeeds Does Federal Evidence Rule 608(B) Exclude?--Imwinkelried vs. Rothstein

Paul F. Rothstein

Georgetown University Law Center, rothstei@law.georgetown.edu

This paper can be downloaded free of charge from:

https://scholarship.law.georgetown.edu/facpub/1511

http://ssrn.com/abstract=2662676 


\title{
COMMENT ON PROF. IMWINKELRIED'S “FORMALISM v. PRAGMATISM IN EVIDENCE: RECONSIDERING THE ABSOLUTE BAN ON THE USE OF EXTRINSIC EVIDENCE TO PROVE IMPEACHING UNTRUTHFUL ACTS THAT HAVE NOT RESULTED IN CONVICTION"
}

\section{JUST WHAT EVIDENCE OF WITNESS MISDEEDS DOES FEDERAL EVIDENCE RULE 608(b) EXCLUDE?---IMWINKELRIED vs. ROTHSTEIN}

\author{
By Paul F. Rothstein ${ }^{1}$
}

Prof. Edward Imwinkelried, one of the country's most renowned Evidence scholars, in a recent article in this journal, ${ }^{2}$ perceptively identifies three specific examples of evidence of a witness's prior unconvicted-for misconduct which he correctly believes should be admissible to impeach the witness's credibility in the discretion of the trial judge:

1. Evidence of demonstrably false previous accusations of rape against the present defendant by the complaining witness in a rape prosecution (assuming the rape shield would not exclude ${ }^{3}$ ) which the witness will not admit to during cross examination;

2. Documentary evidence proving an unrelated misdeed of a testifying witness clearly evincing the witness's lack of credibility, where the witness himself on cross exam could

\footnotetext{
${ }^{1}$ Professor of Law, Georgetown University Law Center, specializing in Evidence. He is the author of numerous books and articles on Evidence and related matters including among others EVIDENCE: CASES, MATERIALS AND PROBLEMS ( ${ }^{\text {th }}$ Ed. 2013 plus electronic supplement 2015) (with Myrna Raeder \& David Crump) and a series of articles and postings on recent developments under the Confrontation Clause which have made SSRN's "Top Ten" lists, including Unwrapping the Box the Supreme Court Justices Have Gotten Themselves Into: Internal Confrontations Over Confronting the Confrontation forthcoming Fall 2015, How. L. Rev., currently posted on SSRN; Ambiguous-Purpose Statements of Children and Other Victims of Abuse Under the Confrontation Clause, forthcoming Fall 2015, S.W. L. Rev., currently posted on SSRN; Two Excursions into Current U.S. Supreme Court Opinion-Writing, https : //casetext . com/posts/two-excursions-into-current-us-supremecourt-opinion-writing; and Comment on the Supreme Court's Decision in ohio $v$. Clark: The Confrontation Clause Evolves, https://casetext.com/posts/acomment - on - the-supreme-courts-decision-in-ohio-v-clark. Rothstein has been a Fulbright Scholar at Oxford University England, a trial lawyer in Washington, D.C., and an advisor on the Federal Rules of Evidence (hereinafter "F.R.E.") to the U.S. Congress, the U.S. Department of Justice, and several Washington law firms and government agencies, and on Evidence and related matters to several nations and U.S. states.

${ }^{2}$ Edward J. Imwinkelried, Formalism Versus Pragmatsm in Evidence: Reconsidering the Absolute Ban on the Use of Extrinsic Evidence to Prove Impeaching, Untruthful Acts That Have Not Resulted in a Conviction, 48 CREIGHTON L. REV. 213 (2015).

${ }^{3}$ A rape shield-for example F.R.E. 412-excludes from evidence the sexual history of complainant. But frequently rape shields are held not to cover evidence of previous false rape accusations either because the evidence is not deemed evidence of "sexual behavior" or "sexual predisposition" of the type banned by the shield, or because, as in Prof. Imwinkelried's specific example, the previous accusations were against the defendant himself. Conduct that is previous conduct involving the defendant himself, is usually exempted from the shield, as it is in, e.g., F.R.E. 412(b) (1) (B). See Paul F. Rothstein, FEDERAL RULES OF EVIDENCE 244, 248 (3d Ed. 2014-15).
} 
authenticate the document so it could be used conveniently and expeditiously without undue time consumption; and

3. Evidence of the result in an unrelated previous civil action, for example where the witness was a party and an adverse verdict clearly establishes his position was fabricated, or where he was only a witness but the verdict makes it clear the trier of fact rejected his contention as fabricated.

I agree with Prof Imwinkelried that these can be powerful pieces of evidence on occasion and should be admissible in the judge's discretion upon consideration of such factors as probative value on the issue of the witness's credibility, time consumption, and prejudice. But Prof. Imwinkelried and I disagree as to whether the literal language of Federal Rule of Evidence 608(b) bans them absolutely. Prof. Imwinkelried believes it does, and therefore should be amended. I believe it does not and therefore does not require amendment.

\section{THE ARGUMENT}

Rule 608 (b) bans evidence of a witness's unconvicted-for misdeeds if proving them involves using "extrinsic" evidence, no matter how powerfully probative of lying they are, how little time they would consume to present, and how little prejudice they might entail. "Extrinsic" (as opposed to "intrinsic") evidence is evidence adduced through means other than cross examination of the witness being impeached. For example, a misdeed is proved "extrinsically" if the way it is evidenced is by independently introducing other witnesses, documents, or recordings that attest to the witness's commission of the misdeed or provide details about it. ${ }^{4}$

Imwinkelried implies his three numbered instances (above) are merely examples and that there are many other instances, too, where evidence of witness misdeeds demonstrating the witness's non-veracity should be discretionarily admissible even if extrinsically proved, but which the Rule's blanket extrinsic evidence ban allows only on cross examination. His whole argument, however, hinges on the three examples. He cites cases in which he says courts have recognized the value of the kind of evidence in his examples and have found it necessary to violate the rule to let it in, and other cases where he says the courts have refused to do so even though it would be desirable to let the evidence in. ${ }^{5}$

It is my contention that it is only a misconstruction of Rule 608(b) that would preclude discretion to admit his three examples of evidence. Under a proper construction, the evidence is not excluded and the Rule therefore does not need revision. The courts that want to admit the evidence do not need to disregard the rule. The evidence can be admitted perfectly consistently with the rule. Further, Prof. Imwinkelried has not convincingly shown that there is other deserving evidence outside of his three examples that is banned by the Rule.

\footnotetext{
${ }^{4}$ See, defining extrinsic evidence, Paul F. Rothstein, Myrna S. Raeder, \& David Crump, EVIDENCE IN A NUTSHELL 173 ( $6^{\text {th }}$ Ed. 2012); Rothstein, note 3 supra, at 441 et seq.

${ }^{5}$ See Imwinkelried, supra note 2, at 218-19, 228-32..
} 
Prof. Imwinkelried's argument regarding the three examples relies on two misconceptions, though each has some support in previous (but misguided in my opinion) authority. The first misconception is that Rule 608 applies to all unconvicted-for misdeeds of a witness offered to impeach the witness's credibility whatever the theory of impeachment. In fact, the Rule only applies where the theory is showing a bad character regarding credibility. This first mistake is manifest in his example \#1 above, prior false allegations of rape against the present rape defendant.

The second misconception is this. He is under the misconception that even if proving the misdeed can be completely accomplished through cross examination, the evidence is still "extrinsic" and banned by the terms of 608(b) if it has anything to do with a document or a previous judicial event. This applies to his \#2, documents acknowledged by the witness during cross examination, attesting to the prior unrelated misdeed involving lying, and his \#3, a previous unrelated civil case event indicating lying, adduced through the present cross examination. ${ }^{6}$

\section{The Terms of Rule 608(b)}

In pertinent part, Rule 608(b) provides:

Except for a criminal conviction under Rule 609, extrinsic evidence is not admissible to prove specific instances of a witness's conduct in order to attack...the witness's character for truthfulness....But the court may, on cross examination, allow them to be inquired into if they are probative of the character for...untruthfulness of...the witness...."

A few terms in the rule that are instrumental to our inquiry need further explaining: "Extrinsic" evidence is generally defined as evidence other than that adduced during cross examination of the witness being impeached. In other words, although the evidence is addressed to impeaching the credibility of this witness, it is introduced through another witness, or through

\footnotetext{
${ }^{6}$ My terminology labels these as "misconceptions" but the reader should be aware that both Prof. Imwinkelried's view on each of them (including the view of authorities on which he relies) and my view are both reasonable alternative views of the legal concepts involved. It is not that I think his view is unreasonable or insupportable; just that, of course, I believe mine are preferable. This is a debate between reasonable scholars, both of whose interpretations are legitimate and respectable. It is a difference of opinion, in the highest traditions of legal scholarship. The differing views are presented for the reader to select between. This entire paper should be read in that light.
} 
a document, a recording, or some other item introduced independently. ${ }^{7}$ "Character for truthfulness or untruthfulness" means a proclivity of the witness to be truthful or untruthful that may surface in a variety of matters. ${ }^{8}$

Let us examine more closely the three evidence examples identified by Prof. Imwinkelried that he alleges are absolutely excluded by a literal reading of Rule 606(b), to see if they really are so excluded.

Prof. Imwinkelried's Example \#1: Extrinsic Evidence of Prior Clearly False Accusations of Rape by the Same Complaining Witness Against the Current Rape Defendant ${ }^{\underline{9}}$

In this example the offered evidence consists of some kind of extrinsic evidence like testimony of another person or a record establishing the prior accusations and their falsity. In other words, the evidence is not just an inquiry and response on cross examination of the complaining witness (which would be called "intrinsic" evidence and which clearly would be allowed insofar as Rule 608(b) is concerned). The thing that allegedly makes the evidence inadmissible under 608(b) is its "extrinsic" mature-its "non-cross-exam" nature. If the evidence is confined just to cross examination, there is no conceivable problem posed by 608(b).

But, under a proper construction of Rule 608(b), this evidence, whether in the extrinsic or intrinsic form, would not be subject to 608(b) at all! The prior incidents here (the prior false allegations of rape) are not offered as showing the witness has a general "character" for incredibility (the only kind of impeachment covered by 608(b)), but rather are offered to show specifically that the complaining witness lies about rape by this accused-i.e. has a motive to "get” this defendant. ${ }^{10}$ By its express terms, Rule 608(b) applies only when a "character" for

\footnotetext{
${ }^{7}$ See U.S. v. Thomas, 467 F.3d 49 ( $1^{\text {st }}$ Cir. 2006), cert. denied 549 U.S. 1294 (2007); U.S. v. Martz, 964 F.2d 787 (8 Cir. 1992); U.S. v. Brooke, 4 F.3d 1480 (9 $9^{\text {th }}$ Cir. 1993).

${ }^{8}$ See U.S. v. James, 609 F.2d 36 (2d Cir. 1979); Rothstein, supra note 3 at 440, 445, 446; Advisory Committee Note to Rule 608, 56 F.R.D. 183, 268 (1973).

${ }^{9}$ This example is set forth at Imwinkelried, note 2 supra, at 230 et seq.

${ }^{10} \mathrm{My}$ analysis would be the same even if the false allegations made by the victim and offered by the defendant here were allegations against others than the defendant.
} 
incredibility is being shown. ${ }^{11}$ Here the effort is more properly described as impeachment by showing a particular motive or bias. ${ }^{12}$

"Character" is a very general propensity consisting of a broad trait like "dishonesty", "untrustworthiness", "unreliability", "violence” etc. While we might say a complaining witness has an "untrustworthy character," we would be doing violence to language to say "the complaining witness has a character to falsely accuse Daniel Defendant of rape" although we might say "she has a propensity to do so." A specific propensity is different from a charactertype propensity, which is a general propensity manifesting itself in a wide variety of circumstances. ${ }^{13}$ The impeachment of the witness here is not proceeding on a theory of a general character for untrustworthiness, which is all that is covered by Rule 608(b). It is rather proceeding along the lines of a specific propensity to accuse this specific defendant specifically of rape. The main advisory committee note for Rule 608(b) ${ }^{14}$ as well as many cases, ${ }^{15}$ make clear that 608(b)'s strictures-including the ban on extrinsic evidence--do not apply if the purpose of the offer of an incident of the witness's wrongdoing is not to show a general character for incredibility, but rather some other form of impeachment more specifically focused on the facts of the present case. ${ }^{16}$ There is a good reason for treating the more specifically focused impeachment more receptively than impeachment by character showings. The former is much more probative and less susceptible to prejudice and exaggeration.

It may even be that this prior-false-allegation evidence should not be deemed impeachment evidence at all, but rather substantive evidence, going directly to whether the rape

\footnotetext{
${ }^{11}$ Under F.R.E. 404(b), which is the master rule on character, it is expressly recognized-as under the law of every state ib the ubion-- that other wrongs used to show "motive", "plan", or a very specific pattern or "modus operandi" to do very specific things or things in a certain way, do not constitute a character showing. See Paul F. Rothstein, Comment, The Doctrine of Chances, Brides of the Bath, and a Reply to Sean Sullivan, 14 J. LAW, PROBABILITY AND RISK 51, at 51-52 (2015). This non-character showing is what we have here.

${ }^{12}$ Lest I be misunderstood to be saying this is the only way to look at what character is, what form of impeachment is involved here, and how Rule 608(b) should be interpreted on these matters, see note 6 , supra.

${ }^{13}$ See Paul F. Rothstein, Intellectual Coherence in an Evidence Code, 28 LOY. (L.A.) L. REV. 1259 at (1995); Rothstein, supra note 11 at 60-61.

${ }^{14}$ See first few lines of Advisory Committee Note to Rule 608, supra, note 8;

${ }^{15}$ See e.g. U.S. v. James, 609 F.2d 36 (2d Cir. 1979) (impeaching by misdeed to show improper bias or motive rather than general character for incredibioity, is not within 608(b)); U.S. v. Ray, 731 F.2d 1361 (9 ${ }^{\text {th }}$ Cir. 1984) (semble); U.S. v. Garcia, 900 F. 2d 571 (2d Cir. 1990) (semble as to impeachment by contradiction); U.S. v. PerezPerez, 72 F.3d 224 ( $1^{\text {st }}$ Cir. 1995) (semble); cf. U.S. v. White, 405 F.3d 208 ( $4^{\text {th }}$ Cir. 2005) (semble as to substantive use).

${ }^{16}$ A classic example where 608(b) does not apply to an incident of wrongdoing by the witness when the wrongdoing is offered on another theory than impeachment of general credibility character, would be where the defense attempts to show that a prosecution witness has committed another unrelated crime and has not been prosecuted for it, suggesting that the witness is beholden to the prosecution and that is why the witness is testifying in this case for the prosecution. This is impeachment by bias or motive, not covered by Rule 608(b), even though the offer is of a specific instance of wrongdoing committed by the witness. See James and Ray, note 15 supra.
} 
occurred. In that event, it would not be subject to the ban on extrinsic evidence of Rule 608(b) at all, since that rule deals only with evidence offered on the issue of witness credibility. ${ }^{17}$

Prof. Imwinkelried's Example \#2: A Document Showing an Unrelated Falsity (Not Convicted For) Perpetrated by the Witness ${ }^{18}$

Presumably what we are talking about here, under Prof. Imwinkelried's second example, is a document that establishes that a present witness told an untruth on another particular occasion - an untruth relating to another matter than one involved in the particular litigation. Thus, unlike example \#1 above (prior false rape allegations), the effort of the offering attorney here would be the kind of impeachment--impeachment of character for credibility--that is covered by Rule 608(b). The untruthful incident here has not resulted in a conviction, because that would be covered by Rule 609 instead. So what we have here might be, for example, a document from the IRS showing a witness in a murder trial lied on his tax return (assuming we can get around the hearsay rule by invocation of the "not for truth" concept or the public records hearsay exception ${ }^{19}$ ).

The question here, then, is whether this is indeed "extrinsic" evidence, which, when impeachment of character-for-credibility is attempted, is barred by the express terms of 608(b). Prof. Imwinkelried is of the belief that it is extrinsic evidence and therefore is so barred. ${ }^{20}$ But a closer look reveals that it may not be extrinsic evidence. That depends upon some additional facts, which we take up in the following paragraphs.

In Prof. Imwinkelried's example of this kind of evidence, he postulates that the document will be authenticated by the witness himself. This is why Prof. Imwinkelried thinks the document should be discretionarily admissible, even though he believes the strict terms of 608(b) make it automatically inadmissible. He argues it should be admissible (if other Rules like 403 are satisfied) because it will be authenticated by the witness himself. Thus it will not entail the undue time consumption that 608(b)'s ban on extrinsic evidence was intended to prevent. It could, however, be argued that for this very reason, it is not "extrinsic" evidence at all. Extrinsic evidence is evidence that would take time beyond the cross examination to introduce. ${ }^{21}$

\footnotetext{
${ }^{17}$ See White, note 15 , supra. This might also be called impeachment by contradiction, also not covered by the rule. See Garcia, note 15 supra..

${ }^{18}$ This example is set forth at Imwinkelried, note 2 supra, at 232.

${ }^{19}$ See Paul F. Rothstein, Myrna S. Raeder, \& David Crump, EVIDENCE IN A NUTSHELL 393-94 (6 ${ }^{\text {th }}$ Ed. 2012)

(describing the "truth of the matter asserted" concept); F.R.E. 803(8) (public records hearsay exception).

${ }^{20}$ Imwinkelried, supra note 2 at 218, 232.

${ }^{21}$ If the witness refuses to authenticate, then of course it would clearly be extrinsic evidence if the lawyer offering the document wishes to go further and get the evidence in, because that would require another witness, presumably.
} 
Nevertheless, introducing a document does seem like it comes within a common-sense definition of extrinsic evidence, whether the document is introduced during cross examination, or during the cross examiner's next chance to put on his own evidence (say his rebuttal case). Let us accept this proposition, i.e., that the document is extrinsic evidence whenever it is offered. Then the answer to the question whether we have extrinsic evidence in Prof. Imwinkelried's example depends upon whether in the example, the document is itself being offered into evidence, or whether when the witness we are impeaching himself authenticates the document (as stipulated in the example), the witness also admits the truth of what is recited in it-in other words, admits not only that the document issued from the IRS to him (which is all authentication actually involves), but also admits that the document is correct that the witness lied to the IRS. If he admits the latter, then the document is not itself being introduced; rather, the witness has adopted its contents into his testimony. In other words, he has testified on cross examination that he lied to the IRS. This is clearly not extrinsic evidence. It is intrinsic evidence. It is a part of the cross examination.

The 2003 Advisory Committee Note attending an amendment to Rule 608 seems to support Imwinkelried's position that this is extrinsic evidence, regardless of the distinction I have made regarding the witness's adoption of the content. ${ }^{22}$ That Committee Note--which in other respects is absolutely superb--refers for support to an ambiguous comment by justly esteemed evidence expert Prof. Stephen Saltzburg which says that certain forbidden extrinsic evidence cannot be "tucked into" a cross examination in order to escape the ban on extrinsic evidence. ${ }^{23} \mathrm{I}$ believe that view (if it is indeed the view of these two authorities) is mistaken both conceptually and practically, and does violence to the plain meaning and legal meaning of the word "extrinsic" in the rule. ${ }^{24}$

To the extent the 2003 Advisory Committee Note suggests that adoption of the content of the document by the witness during cross exam, is banned extrinsic evidence, the Note is out-ofkeeping with the intent of the original Advisory Committee Note written by the original drafters of Rule 608(b) which seemed to say that anything that was wholly done on cross examination of the witness-being-impeached would not be considered extrinsic. ${ }^{25}$

\footnotetext{
${ }^{22}$ Advisory Committee Note to 2003 Amendment to Federal Rule of Evidence 608, reproduced in Appendix I in Rothstein, note 3, supra, at 1043.

${ }^{23}$ Stephen A. Saltzburg, Impeaching the Witness: Prior Bad Acts and Extrinsic Evidence, 7 CRIM. JUST. 28, 31 (Winter 1993). At least one court has directly addressed the "tucking in" comment and rejected it. U.S. v. Dawson, 434 F.3d 956 ( $7^{\text {th }}$ Cir. 2006), cert. denied, 549 U.S. 1101 (2006).

${ }^{24}$ Again, lest I be misunderstood to be saying that such view is unreasonable, see my footnote 6 , supra. I am just saying we have a legitimate, respectable scholarly difference of opinion, both opinions deserving consideration by the reader.

${ }^{25}$ See Advisory Committee Note supra note 8, at subdivision (b).
} 
If the witness does not admit that the document correctly reports that he committed the misdeed, and the document itself is offered (whether during the cross examination or later, independently) then the document clearly is extrinsic evidence as banned by 608(b), and properly should be excluded, in my view, for the reasons expressed in the next paragraph below and in the section of this article labeled "conclusion."

Professor Imwinkelried may believe that where the witness does not make this admission, there should be judicial discretion to allow the extrinsic evidence. Imwinkelried would argue that, depending on the exact facts, the evidence may be important and the witness should not be encouraged to commit perjury by making a false denial of the misdeed knowing extrinsic evidence cannot contradict him. But I think the time and distraction into collateral matters overrides any slim probative worth the extrinsic evidence is likely to have. Some jurisdictions don't allow intrinsic or extrinsic impeachment by misdeeds not resulting in convictions, believing that the balance comes out against admission even when the inquiry is narrowly confined to cross examination. ${ }^{26}$

Prof. Imwinkelreid does have a point that some witnesses may be encouraged to commit perjury and deny the prior misdeed if the inquiry is allowed on cross examination and the witness's perjurious denial in response cannot be followed up by extrinsic proof of the misdeed. ${ }^{27}$ Imwinkelried argues that other incentives against perjury here are weak: that perjury prosecutions in this situation are rare as a matter of prosecutorial discretion, and that there is a privilege against civil liability in many jurisdictions in connection with being a witness in a case ${ }^{28}$ Nevertheless, I think the inducement to perjury here constitutes a rather small risk. Witnesses by and large are still afraid of committing perjury and don't think they are safe from perjury-based civil or criminal proceedings. Anyway, Prof. Imwinkelried's solution still gives the judge discretion to exclude extrinsic follow-up, ${ }^{29}$ and the judge usually would do so. Thus there would still be some temptation to perjury. At any rate, if perjury in this situation is a substantial problem, that is an issue best addressed by reforming perjury law, tort law (the litigation privilege) and prosecutorial practices.

Prof. Imwinkelried's Example \#3: Incidents Repudiating the Witness that Occurred in Connection With Prior Unrelated Litigation ${ }^{30}$

According to Prof. Imwinkelried, this category includes evidence of the result in a civil action, for example where the witness was a party and an adverse verdict clearly establishes his

\footnotetext{
${ }^{26}$ Paul F. Rothstein, Myrna S. Raeder, \& David Crump, EVIDENCE IN A NUTSHELL 173 (6 $6^{\text {th }}$ Ed. 2012).

${ }^{27}$ Imwinkelried, supra note 2, at 238-40.

${ }^{28} \mathrm{Id}$.

${ }^{29}$ See references to Rule 403 and advocacy of a discretionary standard in Imwinkelried, note 2, supra, particularly at 240-41 and summarized in his conclusion appearing at 242 .

${ }^{30}$ This example is set forth at Imwinkelried, note 2 supra, at 228 et seq.
} 
position as a party was fabricated, or where he was only a witness but the verdict makes it clear the trier of fact rejected his contention as fabricated. The prior civil action we assume is unrelated to the subject of the present trial, because otherwise the point made by me under example \#1 above, to the effect that this is not character evidence governed by 608(b) at all, would apply. In other words, the evidence here is offered to show a propensity to lie in general, not just about the matter on which the witness is testifying in the present case.

Imwinkelried believes this evidence is excluded automatically by 608(b)'s ban on extrinsic evidence whether it is just referred to in a question-and-answer on cross (which he would call "tucking in") or goes beyond that by physically introducing the documents (or a recording or other witness) establishing the previous judicial event casting doubt on the witness. ${ }^{31}$ He thinks they both should be allowed subject to 403 discretion. ${ }^{32}$

I believe the former form ("tucking in") is not extrinsic evidence, but rather is intrinsic evidence because it takes place entirely on cross examination and involves introducing no other evidence than the question-and-answer there. Thus it is not excluded by 608(b)'s automatic extrinsic-evidence ban and consequently is admissible subject to 403 discretion. In contrast, the latter form (physically introducing other evidence) is extrinsic evidence subject to 608(b)'s automatic ban, and rightfully so. My reasoning on all these points is the same as those I advanced above in my discussion of Imwinkelried's example \#2 (documents establishing the witness's misdeed) and in my section labeled “conclusion” below. ${ }^{33}$ In essence Example \#3 is very like Example \#2.

Briefly stated, I am saying regarding this \#3, that if the witness can be gotten to admit during his cross exam the occurrence of the civil adverse event, the fact that the cross examiner mentioned the event during cross in order to elicit the admission, is not extrinsic evidence and consequently is not banned by 608. Nor is the witness's admission, since it all takes place in cross examination. The "tucking in" point and the 2003 Advisory Committee Note, are wrong on this. ${ }^{34}$ So, the entire exchange would be admissible, subject to Rule 403 discretion.

Suppose the witness does not admit it occurred or admits and attempts to explain it. Then any attempt of the impeaching attorney to do more than orally explore or refute during cross the witness's denial or explanation-for example if the attorney attempts at any point to physically introduce some other evidence to explore or refute it--would properly in my view, be banned as extrinsic, for the reasons stated. It would not be worth the downside risks. Inducement to perjury is not a significant concern. ${ }^{35}$

\section{CONCLUSION}

\footnotetext{
${ }^{31}$ See Imwinkelried, note 2 supra, at 228-29.

32 Id.

${ }^{33}$ See text between notes 20-27 supra and between notes 36-41 infra and surrounding text.

${ }^{34}$ See text between and surrounding footnotes 22-25 supra.

${ }^{35}$ See text between and surrounding notes $27-29$ supra and 41-42 infra..
} 
Prof. Imwinkelried argues that 608(b) needs amendment to allow the judge to admit a witness's unconvicted misdeeds that indicate incredibility regardless of whether the misdeed is intrinsically or extrinsically adduced, whenever in an individual case the evidence is found by the judge to be probative on credibility to a degree outweighing potential prejudice, confusion, and time consumption.

Prof. Imwinkelried's whole case is based almost entirely on his three enumerated examples. These are his "proof" that certain evidence of misdeeds of witnesses can on occasion be very good economical evidence of incredibility yet will be banned by the terms of 608(b).

I submit that Rule 608(b) does not absolutely ban the evidence in his three categories and that therefore the judge can often admit it in her/his discretion. This is because in some instances the evidence is not the kind of character evidence covered by the Rule in the first place. This is the case in his \#1, prior false rape allegations against the defendant. In other instances the evidence is not banned because it is not really "extrinsic." This is the case in his \#2, documents proving an unrelated lying incident, to the extent the witness admits the contents of the document; and his \#3, unrelated civil results suggesting lying, to the extent the civil event that challenges the witness's credibility can be shown entirely through the cross examination of the witness.

Since there is no absolute ban, the judge indeed often already has the weighing discretion to admit deserving evidence in these categories that Prof. Imwinkelried advocates. All relevant evidence (which these categories unquestionably contain) that is not within a ban, is subject to Rule 403, which grants such judicial discretion. ${ }^{36}$

I further submit that when Imwinkelried's \#2 (documents attesting to the unrelated lying incident of the witness) and \#3 (unrelated civil results suggesting a propensity to lie) are offered via truly extrinsic evidence (for example via documents or witnesses truly introduced independently of the cross examination), they should automatically be excluded as 608(b) does since they are almost always of marginal utility, and I therefore do not agree with Imwinkelried that there should be discretion to admit them. They would normally be too time consuming or carry things too far afield for their legitimate worth. The fact-finder would tend to get confused about what wrongdoing is actually the central focus of the trial. It is not worth the risk of a trial within a trial that in all fairness would necessarily be engendered. It should be noted again in this regard that many jurisdictions absolutely exclude even wholly intrinsic evidence of this kind as not worth the time and prejudicial distraction, and not worth arguing over, even though intrinsic evidence is confined to cross examination where these downside dangers are at a minimum. ${ }^{37}$

Whether intrinsically or extrinsically adduced, character evidence of this sort involves a rather diffuse and easily exaggerated but actually very weak form of proof--a general character for lying offered to prove lying on a particular occasion. Lots of literature questions whether

\footnotetext{
${ }^{36}$ See Paul F. Rothstein, Myrna S. Raeder, \& David Crump, EVIDENCE IN A NUTSHELL 72-84 (6 $6^{\text {th }}$ Ed. 2012).

37 Paul F. Rothstein, Myrna S. Raeder, \& David Crump, EVIDENCE IN A NUTSHELL 173 (6 ${ }^{\text {th }}$ Ed. 2012).
} 
character showings have any predictive power at all. ${ }^{38}$ It may (or may not!) be worth spending a little capital on such evidence during cross examination, where the negative effects are low, but certainly not when the evidence goes beyond the cross examination. And, in the normal case, the extrinsic evidence banned by 608(b) can be expected to add little to what could be gotten through cross examination.

Thus discretion to admit the extrinsic evidence exhorted by Imwinkelried is in my opinion a bad idea. An automatic ban on the extrinsic evidence of general character for credibility as 608(b) imposes is appropriate and preferable to spending time, effort, expense, argument, and judicial resources on an unpredictable individualized discretionary judgment on the facts of each particular case.

Aside from Prof. Imwinkelried's three examples, I doubt that there are other instances where extrinsic unconvicted-misdeed evidence ${ }^{39}$ offered to show a bad credibility-character is ever worth the downside risks we have discussed. Rarely if ever will there be other important kinds of evidence excluded by the Rule's ban. In my view, the extrinsic evidence that the Rule's ban excludes - if the Rule is correctly interpreted--is almost always of marginal significance, can frequently be suggested by intrinsic evidence, and is normally outweighed by the downside dangers discussed. As noted, many jurisdictions exclude this kind of evidence even if it is only intrinsically offered. Despite the fact that the downside risks are minimized when the evidence is intrinsic, these jurisdictions still feel the risks outweigh the benefits of this character evidence.

When it seems fairly certain in advance that almost all evidence in a category-like the extrinsic evidence of credibility character that 608(b) bans--will be of marginal significance or time consuming, prejudicial, and confusing beyond its worth, a blanket rule of inadmissibility is to be preferred over a rule of judicial discretion, which promotes litigation over how the discretion should be exercised on the facts of each particular case before individual judges who have particular proclivities, and fosters unpredictability, dis-uniformity, and consequent unfairness as among like cases.

Indeed, by the same token as argued by Prof. Imwinkelried for this evidence, it could be argued that almost everything covered by the entire Federal Rules of Evidence, should have been left to judicial discretion on the facts of each particular case, rather than subjected to the exclusionary rules that exist in that body of rules. After all, occasionally an important and economical piece of evidence might be excluded by these exclusionary rules. But for the reasons discussed above, the Rules subject many areas to rule-mandated inadmissibility. One such area, quite properly, is the area we are concerned with here, that is, extrinsic unconvicted misdeed

\footnotetext{
${ }^{38}$ The writings of Prof. David Leonard collected much of this literature including psychological findings. See, e.g., David P. Leonard, The Use of Character to Prove Conduct: Rationality and Catharsis in the Law of Evidence, 58 U.Colo. L. Rev. 1 (1986-88).

${ }^{39}$ Remember, we are talking about non-convictions. The solidity and economy of proof makes convictions a different case. See F.R.E. 609.
} 
evidence to show credibility character. A good case could even be made that unless the evidence is solidified in a conviction, even the intrinsic form should be banned. ${ }^{40}$

I therefore conclude that Rule 608(b) properly automatically bans extrinsic evidence of unconvicted-for misdeeds offered to show bad credibility-character. Although that way we might occasionally be excluding something that on balance is of some legitimate value, such cases will be rare. Having a predictable uniform rule-rather than constantly litigating the balancing issue with the judge and on appeal-- is more important in this area.

Professor Imwinkelried throughout his article argues that there is no extrinsic evidence ban regarding other forms of credibility impeachment such as showing the witness made prior inconsistent statements, has a bias, has poor perceptual ability or memory, has been convicted, has a bad reputation for veracity, or is contradicted by other witnesses or other witnesses have a bad opinion of his veracity. Imwinkelried asks why those forms of impeachment are treated differently than the misdeed credibility character attack covered by 608(b) that we are discussing in these articles. Why is only this form of impeachment subject to an extrinsic evidence prohibition. The answer is, at least in part, that most of those other forms of impeachment are as a general matter much more probative on the issue of credibility and less likely to be exaggerated by the fact-finder. The impeachment covered by 608 (b) involves an inference from general character, which is a very unreliable and easily exaggerated inference. While it is true that impeachment by general reputation or opinion also involves a weak character inference, the time that kind of impeachment consumes is easily confined.

I do agree with Imwinkelried that letting a witness know he cannot be challenged may occasionally invite perjury - that is, invite the witness to lie by denying a misdeed that he did commit. ${ }^{41}$ Nevertheless, I think this risk is small. Perjury is a crime, and by-and-large witnesses think twice about perjuring themselves, even though it is true that perjury of this kind is seldom prosecuted and there is a civil privilege that may prevent lawsuits against the perjuring witness, as Imwinkelried points out. ${ }^{42}$ But the cost of Imwinkelried's solution would be too great. It

\footnotetext{
${ }^{40}$ Recall that we are not talking about evidence in Imwinkelried's category \#1 (former false rape allegations) which is not this kind of evidence at all. See text between notes 9-12 supra.

${ }^{41}$ See Imwinkelried, note 2 supra, at 238-40.

$42 \mathrm{Id}$. If there is a problem here, it would seem to be one that should be addressed by reform of the law and of prosecutorial practices. Prof. Imwinkelreid's solution, to grant judicial discretion regarding extrinsic evidence, still presents the risk of perjury. There would still be instances where a judge in the exercise of the discretion would disallow the extrinsic refutation of the witness's perjurious denial of wrongdoing. Furthermore, the same inducement to perjury that Imwinkelried decries currently exists in a number of places in Evidence law. Under F.R.E. 405(a), extrinsic evidence contradicting a possibly perjurious denial of a character witness's knowledge of contradicting incidents cannot be adduced (see Paul F. Rothstein, Myrna S. Raeder, \& David Crump, EVIDENCE IN A NUTSHELL 115-5 ( $6^{\text {th }}$ Ed. 2012)); and the collateral matters rule that may disallow extrinsic evidence of a contradiction or inconsistency. Id. at 283-87. And, Rule 403 is a general rule allowing the judge to disallow refutations of falsehoods in many instances. It is true that witnesses in these areas and under Imwinkelried's proposal granting discretion, cannot always predict in advance whether the refutation will be allowed or not, so the "inducement" to commit perjury might be less. Probably, however, under Imwinkelried's proposal a practice
} 
would mean litigating about the admissibility of evidence that almost always is of marginal importance, and too time consuming, misleading, confusing, and prejudicial for its worth.

In sum Prof. Imwinkelried, in his excellent and thought-provoking article, is correct that a number of courts are excluding some evidence in categories \#1, \#2, and \#3 that they shouldn't. He does a service by calling our attention to that. The courts are doing it because they are under the impression that Rule 608(b) by its literal terms demands it. Prof. Imwinkelried believes this is a proper impression and exhorts the revision of Rule 608(b). I believe it is a mistaken impression. But at any rate, he and I agree they should not automatically exclude everything in these categories. He generalizes that there are lots of other instances as well, where deserving evidence is nevertheless banned automatically by the literal terms of 608(b)'s extrinsic evidence prohibition. I do not believe that case has been made.

Nevertheless his article is in the highest traditions of scholarship— to stimulate thoughts and thoughtful debates that might not otherwise have been born, as he has done here and countless times in the past.

would develop of exercising the discretion in favor of excluding extrinsic evidence of misdeeds except in extraordinary cases, and savvy witnesses would know this in advance. 